\title{
PORTO PLANETARIUM - CIÊNCIA VIVA CENTER: FROM A DISSEMINATION PROGRAM TO AN EDUCATIONAL PROGRAM
}

\author{
Ilídio André Costa ${ }^{1,2,3,4}$, Mário João Monteiro ${ }^{2,3}$, Daniel Folha ${ }^{3,4,5}$, Filipe Pires ${ }^{3,4}$, \\ Elsa Moreira ${ }^{3,4}$, Ricardo Cardoso Reis ${ }^{3,4}$, \& Hilberto Silva ${ }^{3,4}$ \\ ${ }^{\prime}$ Agrupamento de Escolas de Santa Bárbara (Portugal) \\ ${ }^{2}$ Faculdade de Ciências da Universidade do Porto (Portugal) \\ ${ }^{3}$ Instituto de Astrofísica e Ciências do Espaço, Universidade do Porto (Portugal) \\ ${ }^{4}$ Planetário do Porto - Centro Ciência Viva, Universidade do Porto (Portugal) \\ ${ }^{5}$ Instituto Universitário de Ciências da Saúde, CESPU - Cooperativa de Ensino Superior Politécnico e \\ Universitário (Portugal)
}

\begin{abstract}
The Porto Planetarium - Ciência Viva Center (PP-CCV) is owned by the University of Porto, but is under the scientific and operational management of the Center for Astronomy / Astrophysics Research of the University of Porto (CIAAUP), which fosters the Institute of Astrophysics and Space Sciences (IA), the largest astronomy research unit in Portugal.

Given the mission enshrined in its bylaws CIAAUP, and therefore PP-CCV, promotes science dissemination, science communication and astronomy teaching. As such, since its creation the PP-CCV has promoted astronomy and science outreach, through a diverse program that has evolved significantly over the years. Dissemination has been a common practice in the form of specific activities for children in school ages, and with distinct activities for non-specialized public.

However, in 2016, an analysis revealed that, even though the science dissemination component was well developed, the educational one, even from a non-formal point of view, was lacking.

The main goal of this contribution is to present the undergoing research which conceived, developed, implemented and evaluated an educational program for the PP-CCV between 2016 and 2018, and continues as an educational program, available in the current school year.

The educational program was conceived based on problem solving through interdisciplinarity, involving the curriculum from Earth and Life Sciences, Physics, Chemistry and Mathematics. It was created to fit the essential learnings, goals / programmatic / curricular guidelines of the subjects in the Portuguese mandatory schooling. At the same time, a new process of direct and continuous interaction with the visitors was added, since the moment they choose a didactic sequence, until it is implemented in their formal education contexts. From start to finish, the whole process is subject of evaluation by the teacher(s) which accompany the school group.

Preliminary research data shows that this strategy, of creating and implementing a dedicated educational program, has prompted the PP-CCV as a mean of formal education. The first year of implementation of this new educational strategy saw an increase of over 3000 visitors from the previous year. After the evaluation of the visit, the results show that $98.57 \%$ consider that it was useful for their students and $98.59 \%$ that it was pedagogically relevant.

This first data analysis already seems to indicate that non-formal interdisciplinary learning strategies are not only feasible, but also facilitate the processes of formal education in "real schools" with "real actors".
\end{abstract}

Keywords: Non-formal education, astronomy, planetarium, educational program.

\section{Porto Planetarium - Ciência Viva Center (PP-CCV)}

In the network of Ciência Viva Centers (CV, 2018), a close collaboration with research units is fairly common. However, the PP-CCV is the only center of this network integrated into a research unit of its the scientific area of intervention - the Institute of Astrophysics and Space Sciences (IA).

The IA (2019): is the largest research unit in the field of Astrophysics in Portugal, encompassing more than two thirds of all active researchers in Space Sciences in the country. It is also responsible for most of the national productivity in international ISI journals in the area of Space Sciences. This is the 
scientific area with the highest relative impact factor and the field with the highest average number of citations per article in Portugal.

The IA is a research unit which resulted from the merger, in 2015, of the Center of Astronomy and Astrophysics of the University of Lisbon (CAAUL) and the Center for Astronomy / Astrophysics Research of the University of Porto (CIAAUP). The latter was a Foundation for Science and Technology - public agency (FCT) research unit hosted by the Center for Astronomy / Astrophysics Research of the University of Porto (CIAAUP): a private, non-profit association, recognized as of public utility. Thus, in 2015 this association started hosting IAas a research unit. The PP-CCV is owned by the University of Porto and CIAAUP is responsible for its scientific and operational management. Given its statutory mission of scientific dissemination, communication and teaching of astronomy, the CIAAUP, and inherently the PP-CCV, have an annual average turnout about 30,000 visitors.

In addition to 62 researchers and an Administration and Services Unit (shared with IA), the PP-CCV currently has: an Executive Director; a Coordinator (who also works as an explainer); two designer / editors; an element responsible for the digital technologies of information and communication (who also works as an explainer); one responsible for social networks / press release (who also works as an explainer); an activities facilitator (in exclusivity) and a highschool teacher.

\section{Science communication, science dissemination and science education}

As already mentioned, the CIAAUP, and by inherence, the PP-CCV has, among other things, statutory missions to promote science communication, astronomy dissemination and support for astronomy teaching in elementary and secondary schools. Thus, as this article intends to address only the educational component of the work carried out in the PP-CCV, it is necessary to clearly define the concepts of science communication, dissemination and teaching support used, in order to better understand the educational program that will be presented.

Quite often, in many academic circles and even institutions that promote scientific communication, the concept of scientific dissemination is intentionally used in a way that distances the latter practice from the work of scientific communication. In this sense, authors such as Kunth (1992), Bueno (2010) and Crato (2016) reserve for scientific dissemination the whole exercise of dialogue between experts (or their mediators) and lay public, which has assumed a mission of social education from its inception. Thus, dissemination plays a central role in captivating the public for science and hence for the promotion of scientific literacy. It informs the public about important topics of present-day science, reveals sources and entices the pursuit of knowledge - it shows science as "another" human creation which is a part of life, of our daily routine and our culture (Crato, 2016). For these authors, the concept of scientific communication emerges as a component of dissemination or diffusion of "content" between expert peers (disciplinary or interdisciplinary).

Yet, for some authors, this apparently clear distinction between the concepts of scientific communication and dissemination is artificial. For example, Lewenstein (2003), Burns, O'Connor, and Stocklmayer (2003) consider that scientific dissemination is included in the generic concept of science communication.

However, the distinction between the concepts of dissemination and teaching of science is less arguable. Nevertheless, the use of the concept of education in different contexts, to the detriment of the concept of teaching, is due to the assumption that one of the missions of the school, besides teaching, is to educate: rather than outline didactic sequences for the understanding of knowledge, the school dwells on the mobilization of knowledge and skills developed by students, and on the reflection of the value system.

Crato (2016) states that, even if they are different concepts, formal education and teaching are organized processes, with programs (and / or curricular goals) with mandatory evaluation moments which contribute decisively to obtain certification.

If dissemination can choose which subjects to use, in order to spark the public interest, even if they are one-off and dispersed, this is not an option with teaching. For dissemination, sparking a taste for science around a specific theme is enough, but for teaching, the goal is the positive assessment of a whole program (with the diversity of themes included), and, more importantly, the mobilization of these skills and knowledge (Costa, Monteiro, \& Costa, 2010). Summing-up: scientific dissemination tends to be fortuitous, while teaching tends to be systematic. 


\section{The design, development, implementation and assessment of the educational program of the PP-CCV}

As seen given the mission enshrined in its bylaws, CIAAUP, and therefore PP-CCV, promote science dissemination, science communication and astronomy teaching. Since its creation, the PP-CCV, has been promoting astronomy and science outreach, through a diverse program that evolved significantly over the years. Dissemination has been a common practice in the form of specific activities for children in school ages, and with distinct activities for non-specialized public. In 2016, an analysis revealed that, although the science dissemination component was well developed, the educational one, even from a non-formal point of view, was lacking.

To solve this problem, CIAAUP asked the Ministry of Education to assign one of its teachers, from primary and secondary education, to the planetarium. The intended profile had the underlying objective to find someone with an interdisciplinary professional training: someone with a degree in Biology-Geology teaching, but with a Master's Degree in Astronomy Teaching.

Thus, one of the components that resulted from the work of this teacher was the design, development, implementation and evaluation of a real educational program for PP-CCV.

\subsection{The educational program of PP-CCV}

The process to outline an educational program, which would make non-formal education in Astronomy at the PP-CCV more efficient, began by analyzing all the existing resources in the PP-CCV itself. In 2016, these resources were crossed-checked with the curricular programs, guidelines and targets of compulsory schooling (from pre-school to secondary school). In 2017, this work was extended to the new framework implemented by the ME: the Profile of Students at the end of mandatory schooling and the Essential Learning, within a framework of Autonomy and Curricular Flexibility. Based on this work, didactic sequences were outlined; for the hands-on labs we produced and/or revised guides for the visitors and of visitation itineraries for the facilitators (in order to standardize the didactic sequences). This was structural work, which could only be carried out with the involvement and in a spirit of effective collaborative work among all the elements of the outreach unit of the PP-CCV.

The result, in 2018, was the layout of an educational program, with twenty-one different didactic sequences, covering all years of mandatory schooling; ten different disciplinary curricular areas and a logic that can, at the option of the teacher, be disciplinary, multidisciplinary or interdisciplinary, according to Pombo (2005) and Levy, Guimarães, and Pombo (1994). In the short term, we intend to deepen this visitation model by providing pre- and post-trip resources, in a rational way as proposed by Orion (1993) and that enhances the work to be developed in the formal contexts of teaching.

This educational program is currently fully implemented. In order to make this possible, it became necessary to introduce a new template for booking visits in the PP-CCV. Thus, all booking requests are analyzed before the visit takes place, in order to verify their adequacy to the students grade and the teachers goals for the visit. To fulfil this goal it became necessary to analyze hundreds of requests and to establish a similar number of direct contacts (telephone, e-mail or face-to-face) with teachers. This work produces detailed weekly work schedule maps for the science communicators, featuring planetarium shows, hands-on labs and other one-off activities, like lectures or telescope observation. In order to avoid large waiting groups of students in the PP-CCV, a new space to develop laboratories was created, thus extending the PP-CCV maximum capacity to 120 visitors per hour, an almost $30 \%$ increase from the previous capacity of 95 visitors.

To have some follow-up from the visiting teachers, a system which produces an attendance certificate from a database was created from scratch and implemented, which also allows teachers to evaluate of the work of the PP-CCV. At the same time, training meetings for teachers were also organized.

For the dissemination of this new educational program, the site of the PP-CCV (http://www.planetario.up.pt/) was restructured and a partnership with Porto Editora SA was established. Thus, this company forwards, to all teachers in their databases and by recruitment group, emails with specific content about the PP-CCV offer for their specific recruitment group.

\subsection{The assessment of the educational program of the PP-CCV}

In the period between September and December (which corresponds to the first academic period), the number of visitors of the PP-CCV, from 2016 to 2017, decreased (minus 450 visitors). However, taking into account only the first three months of implementation of the new educational program (September to December 2017): 
- the number of students who attended laboratory activities increased (over 360 students). Thus, $61 \%$ of students performed laboratories in 2017 (against 46.94\% in 2016). The number of students who did the most adapted didactic sequence to the 7th grade increased (over 1475 students). Thus, 50.59\% of students completed this sequence in 2017 (against 12.87\% in 2016);

- the number of students who completed the didactic sequence more suited to Natural Sciences, Biology and Geology increased (202 more students). Thus, 26.50\% of students completed this sequence in 2017 (against 19.38\% in 2016).

This data set could be a direct consequence of the booking analysis subsequent direct contact with the teachers, but we cannot exclude other factors.

On the other hand, in the first three months:

- Some teachers attending our accredited continued training brought their students to the $\mathrm{PP}-\mathrm{CCV}$;

- the PP-CCV began to be recognized, in training meetings, by the teachers;

- some teachers present in training meetings brought their students to the PP-CCV.

The above data demonstrates a counter-cyclic flow of visitors. In fact, in absolute numbers, there was a decrease in visitors, in line with what happened in previous years. However, the number of visitors in didactic sequences towards the contents of formal education increased significantly.

This trend intensified in the following year with a new tendency - a significant increase in the number of visitors of the PP-CCV. Comparing the 2016/2017 school year, with the 2017/2018, there was an increase of more than 3000 visitors. On the other hand, the monthly average number of visitors who attended a show and a laboratory (a didactic sequence that corresponds to a greater deepening of the contents of formal education), has more than doubled. In the specific case of the laboratories, in 2017/2018 an additional 800 were performed, compared to 2016/2017.

However, the point of the evaluation to the work done is much deeper than a simple numerical analysis of the number of visitors. From our point of view, what would be most helpful for this discussion is how the intervention affected students science knowledge. This was another aspect requested from the work developed by the teacher assigned by the ME.

With this in mind, in 2017, the teacher started the doctoral program in Teaching and Dissemination of Sciences, at the Faculty of Sciences of the University of Porto. Given the small time elapsed, it is understandable that this is a work still in its early stages.

Even so, as early as 2017, a small evaluation questionnaire was drawn up, which is filled, voluntarily, by the teachers, after the visit to the PP-CCV.

The preliminary analyses of 71 questionnaires revealed that:

- $98.57 \%$ considered that the didactic sequence associated to the immersive film was useful for their students;

- $98.59 \%$ considered that the didactic sequence associated to the immersive session was pedagogically relevant;

- $94.37 \%$ directly related the didactic sequence to the formal education curriculum;

- $90.14 \%$ considered that the live part of the session, inside the planetarium, was useful for their students;

- $92,96 \%$ directly related the live part of the session, inside the planetarium, to the formal education curriculum.

Regarding the didactic sequence carried out in a laboratory context, the analysis of the 33 validated questionnaires revealed that:

- $90.91 \%$ considered that the didactic sequence, was useful for their students

- $84,85 \%$ considered that it was an increment to what could be done in their school laboratory;

- $93.93 \%$ directly related the didactic to the formal education curriculum.

The educational program was evaluated as Good by $39.44 \%$ of respondents, and Very good by $57.75 \%$. Furthermore, $100 \%$ considered it very likely that they will return to visit the PP-CCV with their students and $95,65 \%$ would return for a personal visit.

\section{Conclusions}

As we tried to clarify the long road already traveled is actually just beginning. There is a whole range of pre- and post-visit resources to be built, which will enhance non-formal teaching of the PP-CCV in the formal teaching contexts of visitors. On the other hand, the model of non-formal education itself can also be enhanced. Such work will begin after the evaluation of the model which, as it was made clear, is still in a very preliminary stage. 
However, the first data analyses already seems to indicate that non-formal interdisciplinary learning strategies are not only feasible, but also facilitate the processes of formal education in "real schools" with "real actors".

\section{References}

Bueno, W. C. (2010). Comunicação científica e divulgação científica: aproximações e rupturas conceituais. Informação \& Informação, 15(1esp), 1-12.

Burns, T. W., O'Connor, D. J., \& Stocklmayer, S. M. (2003). Science communication: a contemporary definition. Public Understanding of Science, 12(2), 183-202.

Costa, I. A., Monteiro, M., \& Costa, M. (2010). Metodologias interdisciplinares na alfabetização científica dos cidadãos: de uma exigência curricular a um imperativo profissional. Revista Arquipélago Ciências Educação, 11, 89-116.

Crato, N. (2016). As saudáveis diferenças entre a divulgação, o ensino e a investigação. Revue: Revista da Universidade de Évora III, 6, 4-11.

CV. (2018). Rede de Centros Ciência Viva. Retrieved 15 April 2019 from http://www.cienciaviva.pt/centroscv/rede/

IA. (2018). Instituto de Astrofísica e Ciências do Espaço. Retrieved 15 April 2019 from http://www.iastro.pt/ia/index.html

Kunth, D. (1992). La place du chercheur dans la vulgarisation scientifique. Retrieved 14 April 2019 from Délégation à l'information scientifique et technique (DIST): http://science.societe.free.fr/documents/pdf/rapport_Kunth.pdf

Levy, T., Guimarães, H., \& Pombo, O. (1994). A interdisciplinaridade-Reflexão e Experiência. Lisboa: Texto Editora.

Lewenstein, B. V. (2003). Models of public communication of science and technology. Public Understanding of Science, 96, 288-293.

Orion, N. (1993). A model for the development and implementation of field trips as an integral part of the science curriculum. School Science and Mathematics, 93(6), 325-331.

Pombo, O. (2005). Interdisciplinaridade e integração dos saberes. Liinc em revista, 1(1). 